\title{
Limb-use by foraging marine turtles, an evolutionary perspective
}

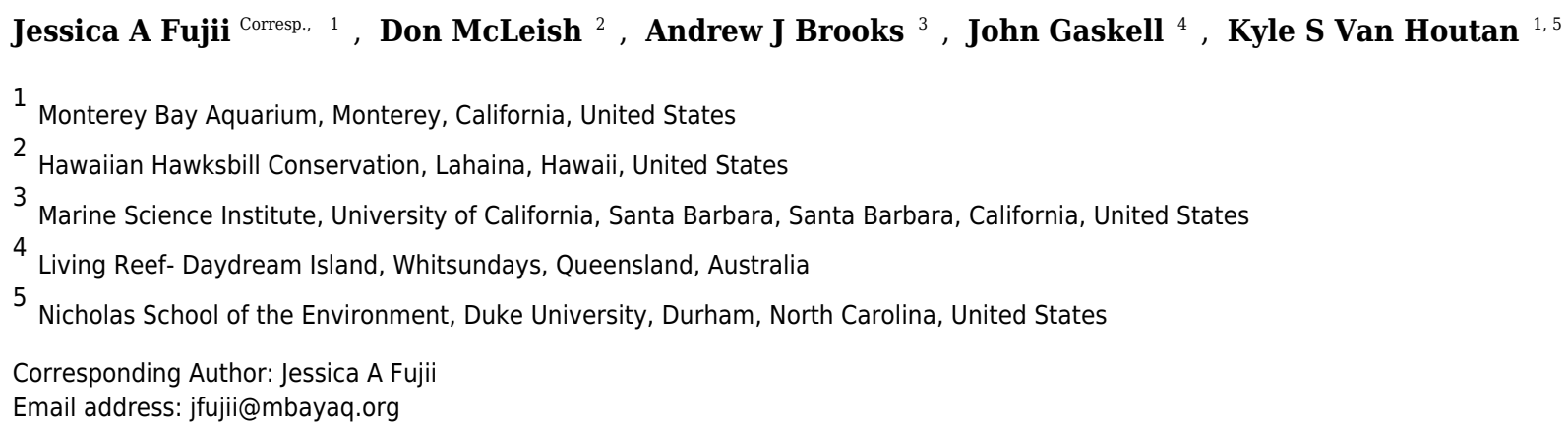

The use of limbs for foraging is documented in both marine and terrestrial tetrapods. These behaviors were once believed to be less likely in marine tetrapods due to the physical constraints of body plans adapted to locomotion in a fluid environment. Despite these obstacles, ten distinct types of limb-use while foraging have been previously reported in nine marine tetrapod families. Here, we expand the types of limb-use documented in marine turtles and put it in context with the diversity of marine tetrapods currently known to use limbs for foraging. Additionally, we suggest that such behaviors could have occurred in ancestral turtles, and thus, possibly extend the evolutionary timeline of limb-use behavior in marine tetrapods back approximately 70 million years. Through direct observation in situ and crowd-sourcing, we document the range of behaviors across habitats and prey types, suggesting its widespread occurrence. We argue the presence of these behaviors among marine tetrapods may be limited by limb mobility and evolutionary history, rather than foraging ecology or social learning. These behaviors may also be remnant of ancestral forelimb-use that have been maintained due to a semiaquatic life history. 
1 TITLE: Limb-use by foraging marine turtles, an evolutionary perspective

2 AUTHORS: Jessica A. Fujii, ${ }^{1}$ Don McLeish, ${ }^{2}$ Andrew J. Brooks, ${ }^{3}$ John Gaskell, ${ }^{4}$ Kyle S. Van Houtan ${ }^{1,5}$

3 AFFILIATIONS:

$4 \quad{ }^{1}$ Monterey Bay Aquarium, Monterey, CA, USA;

$5 \quad{ }^{2}$ Hawaiian Hawksbill Conservation, Lahaina, HI, USA;

$6 \quad{ }^{3}$ Marine Science Institute, University of California, Santa Barbara, CA, USA;

$7 \quad{ }^{4}$ Living Reef - Daydream Island, Whitsundays, QLD 4802, Australia;

$8 \quad{ }^{5}$ Duke University, Nicholas School of the Environment, Durham, NC, USA.

9 Corresponding author: Jessica A. Fujii ${ }^{1}$

10 Email address: jfujii@mbayaq.org 
12

13

\section{Abstract.}

The use of limbs for foraging is documented in both marine and terrestrial tetrapods. These behaviors were once believed to be less likely in marine tetrapods due to the physical constraints of body plans adapted to locomotion in a fluid environment. Despite these obstacles, ten distinct types of limb-use while foraging have been previously reported in nine marine tetrapod families. Here, we expand the types of limb-use documented in marine turtles and put it in context with the diversity of marine tetrapods currently known to use limbs for foraging. Additionally, we suggest that such behaviors could have occurred in ancestral turtles, and thus, possibly extend the evolutionary timeline of limb-use behavior in marine tetrapods back approximately 70 million years. Through direct observation in situ and crowdsourcing, we document the range of behaviors across habitats and prey types, suggesting its widespread occurrence. We argue the presence of these behaviors among marine tetrapods may be limited by limb mobility and evolutionary history, rather than foraging ecology or social learning. These behaviors may also be remnant of ancestral forelimb-use that have been maintained due to a semi-aquatic life history.

\section{Introduction.}

Marine turtles (Chelonioidea Oppel, 1811) and most other marine tetrapods, have evolved body forms that are best suited to move, orient, and minimize drag in a fluid environment rather than using their articulating limbs to directly aid in prey capture or processing (Fish 2016). Due to the limitation of these evolved body plans and the constraints of the aquatic environment, Taylor (1987) predicted mouth-based filter, suction, or ram foraging to be the primary foraging mechanisms for all marine tetrapods. Although the evolution of foraging mechanisms generally coincides with associated morphological traits, such as filter feeding and baleen in Mysticete whales (Deméré et al. 2008), many species have been observed using innovative strategies counter to what their evolved body plans would predict. Following Gould \& Vrba (1982) and Lloyd \& Gould (2017), these traits could be considered exaptations; "traits that were adapted for one evolutionary function, but were later co-opted (but not selected) to serve a different role". Such exaptations can provide insight into an organism's current ecological dynamics (Gould \& Vrba 1982) as well as the evolutionary conditions influencing these novel behaviors.

Despite the predictions of Taylor (1987), a number of marine tetrapods have been documented to use their limbs to directly aid in prey capture, manipulation, and processing (Iwaniuk \& Whishaw 2000). Rudimentary limb-use for foraging is observed in a range of terrestrial and aquatic taxa, therefore, this behavior could have evolved in ancestral tetrapods and was subsequently developed, maintained, or lost in different lineages over time (Iwaniuk \& Whishaw 2000). For those lineages that lost the ability, the use 
44 of limbs to aid in foraging may be an exaptation - wherein limbs evolved for locomotion have been coopted to be used in food handling (Gould \& Vrba 1982). These behaviors (hereafter "limb-use") may improve foraging efficiency, expand ecological niches, and perhaps confer greater resiliency in dynamic or altered environments. Limb-use could also have developed as a result of co-evolution or are secondary adaptations (Lloyd \& Gould 2017), but as suggested by Hocking (2017b), the evolution of forelimbs dedicated to locomotion may have consequently made said limbs unsuitable for feeding purposes. Thus, it seems unlikely that these behaviors would have been selected for under various evolutionary processes. Why limb-use develops in some marine tetrapods, but not others, is not well understood. Hocking et al. (2017b) showed that less-specialized, semi-aquatic marine mammals (Mustelidae, Odobenidae, Otariidae, Phocidae) might retain the use of forelimbs to manipulate prey, but older taxa and taxa more specialized for the aquatic environment (e.g. cetaceans) might rely solely on suction, filter, or ram foraging. Whether this pattern extends to marine turtles has not been previously explored.

Marine turtles are the oldest extant line of marine tetrapods but some still maintain a semiaquatic lifestyle for thermoregulation and breeding (Kelley \& Pyenson 2015). Like many other marine tetrapods, marine turtles predominantly use suction or bite-and-tear foraging strategies to capture and process food (Moreno et al. 2016). To date, however, direct observations of marine turtle foraging mechanisms are somewhat limited, or the methods used (such as critter-cams) limit the ability to assess limb-use due to a narrow field of view (but see: Schofield et al. 2006; Seminoff et al. 2006; Patel et al. 2016). While knowledge of marine turtle diets has significantly improved in recent years with technological innovations (Arthur et al. 2007; Patel et al. 2016; Van Houtan et al. 2016) without direct observations, many aspects of feeding behavior remain overlooked. Here, we describe three marine turtle species - green (Chelonia mydas), hawksbill (Eretmochelys imbricata), and loggerhead (Caretta caretta) - using limbs in the wild to aid in foraging in ways which have not been previously assessed in detail. We set these observations in context with other marine tetrapods known to use their flippers, forelimbs, or tails as direct aids in obtaining or processing food and discuss the role of behavioral, morphological and ecological factors that may limit or promote this behavior.

\section{Materials \& Methods.}

While viewing a fixed-station underwater video from a coral reef in Moorea, French Polynesia we opportunistically observed a hawksbill sea turtle use its limbs while foraging, prompting discussion with experts in the field, and a broader survey for the occurrence and context of this behavior. We documented marine turtle foraging behavior from underwater surveys, web image and video searches (e.g., Google, YouTube, Vimeo, Flickr, Shutterstock), and the published literature. 
For this study, limb-use for feeding was defined as the intentional use of flippers, paws, tails, or feet to directly aid in the capture, processing, or transport of the animal's food while in the marine environment. If we did not find limb-use feeding described in the published literature (e.g. searching Google Scholar and Web of Science), we conducted broader internet searches for video and images using the species' common name or group ("green turtle" or "sea turtle") combined with feeding terms (e.g. "feeding", "foraging", "eating"). Once an initial record was found, we conducted more in-depth searches for that species or group to determine the ecological context of the behaviors. Feeding strategies were grouped into broad behavioral categories and feeding stages based previous study definitions (Hocking et al. 2017b), Table 1).

We defined marine tetrapods similar to previous studies (Kelley \& Motani 2015; Kelley \& Pyenson 2015). We excluded the polar bear (Ursus maritimus) as there is significant genetic admixture with a fully terrestrial species (Miller et al. 2012), and we excluded marine snakes as they lack external limbs. We initially included sea birds, yet limited observations to feeding occurring entirely in the marine environment. Foot-paddling, for example, is observed in a number of Laridae gulls, yet it occurs in terrestrial or mudflat habitats (Tinbergen 1962) and so was not included.

Due the difficulty of observing wild foraging behaviors for many marine tetrapods, the absence of documented limb-use while feeding here does not indicate the behavior does not or cannot occur. In light of this, our intent was to be descriptive, not exhaustive, in comparing the occurrence of these behaviors. Due to the relative rarity of this behavior, we grouped marine tetrapods into taxonomic families for comparisons. We broadly compared evolutionary, morphological, ecological, and behavioral factors to qualitatively determine if the presence of limb-use behaviors followed patterns across marine tetrapod families. Evolutionary relationships and divergence times are from Timetree.org (Hedges et al. 2006).

\section{Results \& Discussion.}

Carr (1967) described hatch-year green turtles using the sharp claw on their foreflippers to swipe and tear food in tanks in captivity. Davenport \& Clough (1985) similarly observed these behaviors in captive juvenile loggerhead turtles. Both studies suggested these behaviors would be limited to juveniles due to undeveloped, weak jaws. Since then, adult loggerhead turtles have been recorded holding mollusks between their foreflippers (Houghton et al. 2000), and digging (using forelimbs to remove benthic sediment) has been opportunistically documented in adult green turtles (Christianen et al. 2014) and loggerhead turtles (Limpus et al. 1994; Preen 1996). In our surveys, we found additional forms of limbuse not previously described, and add hawksbill turtles to the species of marine turtles documented to use these feeding strategies. 
We found four novel types of limb-use by hawksbill, loggerhead, and green turtles. Hawksbill and green turtles were observed using corralling, leveraging, holding, and swiping movements to capture, process, or transport a variety of sponges, cnidarians, macroalgae, and fishes (figure 1a-d, f, Supplemental Material Figure S1, table 1). We also documented loggerhead sea turtles swiping to process benthic mollusks, which is likely a continuation of the holding behaviors described above (figure 1e). Given the apparent rarity of these feeding strategies, it seems unlikely that they are required to consume any of these prey items, but they may aid feeding efficiency and expand foraging or habitat niches.

Limb-use while feeding has been previously reported in eight additional families of marine tetrapods including Balaenopteridae, Delphinidae, Trichechidae, Dugongidae, Mustelidae, Odobenidae, Otariidae, and Phocidae (figure 2, Supplemental Material Table S1). Within these families, ten types of limb-use for foraging have been observed: digging, striking, tossing, kerplunking, leveraging, swiping, holding, pounding, lobtailling, and corralling (table 1). Holding and digging were the most common behaviors seen across families (Kastelein \& Mosterd 1989; Bowen et al. 2002; Marshall et al. 2003; van Neer et al. 2015; Hocking et al. 2017a). Stunning prey included directly striking or tossing as well as indirect so-called "kerplunking" (slapping the water surface with tail to cause a startle response in prey) and was seen only in Delphinids (Domenici et al. 2000; Gonzalez \& Lopez 2000). Lobtail feeding (slapping water surface with tail during bubble-net feeding to corral prey together) is currently exclusive to humpback whales (Megaptera novaeangliae, Weinrich et al. 1992). Sea otters (Enhydra lutris) demonstrated the most diverse and complex forms of limb-use for foraging, including pounding prey against tools (Fujii et al. 2014). To our knowledge, limb-use has not been documented in any other marine tetrapods, but future studies may reveal currently undescribed behaviors. Although publiclyavailable media have increased over time (Kousha et al. 2012), uploading images and videos on public platforms is not a universal practice. As a result, there may be other examples of limb-use that our surveys missed. However, the number of behaviors observed suggests it is still an effective method of documenting natural behavior.

We compared the prey type, relative prey size, and habitat across the marine tetrapods listed above to determine if distinct ecological factors promoted the development of limb-use (Supplemental Material table S1). However, limb-use behaviors were observed in a wide variety of conditions. Benthic feeders consumed bivalves, grasses, macroalgae, sponges, anemones, and hard corals. Epipelagic feeders consumed fish, jellyfish, and small marine mammals. Prey size often exceeded gape size (precluding whole consumption) but relatively smaller prey were also consumed, and included both mobile and sessile species. These factors may still be important factors at the species level, but did not remain constant across marine tetrapod families. Given the disparity of body forms and ecological niches 
141 observed across marine tetrapods, the range of ecological conditions in which limb-use is present is

142 perhaps unsurprising. However, this diversity shows that a variety of conditions can lead to the expression

143 of these behaviors, and provides additional support that many more species may use limb-use strategies

144 that have not yet been documented in the literature.

145 The regular use of limbs for tasks beyond swimming may also promote the development of limb146 use. As noted in Hocking et al. (2017b), limb-use was more common in semi-aquatic mammals who may 147 also use forelimbs for locomotion on land. In marine turtles, although predominately aquatic, females 148 must return to land for nesting and use both fore- and hind-limbs to dig body pits and nesting sites (Carr $149 \&$ Ogren 1959). Additionally, terrestrial basking by marine turtles is female-biased (Van Houtan et al. 150 2015). The wider range of flipper-use by female marine turtles may also result in a female sex-bias in 151 limb-use for feeding. From our observations, all hawksbills we were able to age and sex were putatively 152 determined to be females, but were unable to determine the sex of the other turtles due to limitations in the media. However, Schofield et al. (2006) observed digging by both sexes of loggerheads. Limb mobility may play the largest role in the development of limb-use across marine tetrapods. Foreflipper mobility varies across marine tetrapods due to trade-offs for maneuverability, stability, and propulsion (Fish 2004). Taylor (1987) suggested that the constant need of foreflippers for locomotion and stability in the marine environment would limit their availability for other uses, including foraging. Although foreflippers used in propulsion have greater mobility compared to the foreflippers of taxa that use hindlimbs as the primary source of propulsion (Fish 2004; Kelley \& Pyenson 2015), we found limbuse by species that used both forms of propulsion (Supplemental Material, table S1). The limited mobility of foreflippers may prompt the use of tails in Delphinidae and Balaenopteridae cases, and may also explain the lack of limb-use by penguins and other cetacean families. Of the marine turtle foraging observations we report, all save one (figure $1 \mathrm{~b}$ ) involved foreflipper pronation movements. Figure $1 \mathrm{~b}$ instead shows foreflipper supination while holding prey. Foreflipper pronations are the dominant mechanism marine turtles employ for swimming, crawling on land, excavating body pits for nesting, and aiding thermoregulation while basking (Van Houtan et al. 2015). (such as lunge feeding), that can be analyzed via skull structure in extinct and extant species (Motani et al. 2015), it is currently unknown if there are any detectible physical predictors of limb-use that could be used for studying the origin of this behavior. Given the possible role of forelimb mobility on the presence

171 of limb-use, muscular comparisons may be a future avenue of study as precedence for correlations 172 between limb shape and ecological niche in turtles has been previously shown by Joyce \& Gauthier 173 (2004). If limb-use is an (unselected) exaptation rather than an evolved trait, however, distinct 
174 morphological correlations may be more difficult to identify. Several species of terrestrial or semi-aquatic

175 turtles have also been documented using their forelimbs to assist in processing food (Davenport et al.

176 1984; Lutz et al. 2002), but the limbs of these species are not as specialized in shape as marine turtle

177 foreflippers are for swimming (Joyce \& Gauthier 2004) and so this limb-use is similar to that seen in

178 other terrestrial tetrapods (Iwaniuk \& Whishaw 2000). As marine turtles do not have opportunities for

179 social learning, these behaviors either developed via independent trial and error, or are maintained as an

180 innate behavior (Lutz et al. 2002). If these behaviors are innate, their presence in terrestrial turtles may

181 support the hypothesis that this behavior was present in an ancestral turtle (Joyce \& Gauthier 2004). If

182 this behavior was present when marine turtles evolved, approximately 120 million years ago, then limb-

183 use may have been present in the marine environment almost 70 million years before all other extant

184 marine tetrapods (Bowen et al. 1993; Cadena \& Parham 2015; Kelley \& Pyenson 2015).

185

186

187

188

189

190

191

192

193

194

195

196

197

198

199

200

201

202

203

204

Although flipper morphology and foraging ecologies likely evolved via convergent evolution across marine tetrapods (Kelley \& Motani 2015; Kelley \& Pyenson 2015) it is unknown if limb-use evolved under the same processes. Iwaniuk \& Whishaw (2000) showed that rudimentary limb-use likely first evolved in ancestral tetrapods but was subsequently maintained, developed, or lost in various lineages over time. It is, therefore, possible that the predisposition for this ancestral behavior was maintained as tetrapods returned to the marine environment and only manifests under appropriate modern conditions.

\section{Conclusions.}

The use of limbs to directly aid in foraging, while still relatively rare, is a strategy used by a variety of marine tetrapods. Despite being the oldest extant line of marine tetrapods, this is the first time such a wide range of limb-use has been described in marine turtles. We argue that these limb-use behaviors across marine tetrapods are limited by limb mobility and that the frequent use of forelimbs for other behaviors may promote the development of these feeding strategies. These observations provide additional insight into the diversity and possible evolution of limb-use behaviors.

\section{Acknowledgements.}

J. Seminoff, N. Pilcher, A. Gentry, J. Goldbogen, J. Moxley, M. Staedler, T. Nicholson, M. Murray, A. Johnson, L. Henkel and several anonymous reviewers improved earlier versions of this manuscript. The Coonamessett Farm Foundation provided underwater video. 
205

206

207

208

209

210

211

212

213

214

215

216

217

218

219

220

221

222

223

224

225

226

227

228

229

230

231

232

233

234

235

236

237

238

239

240

241

242

243

244

245

246

247

248

249

250

251

252

\section{REFERENCES}

Arthur KE, O'Neil JM, Limpus CJ, Abernathy K, and Marshall G. 2007. Using animal-borne imaging to assess green turtle (Chelonia mydas) foraging ecology in Moreton Bay, Australia. Marine Technology Society Journal 41:9-13.

Bowen BW, Nelson WS, and Avise JC. 1993. A molecular phylogeny for marine turtles: trait mapping, rate assessment, and conservation relevance. Proceedings of the National Acadeny of Sciences USA 90:5574-5577.

Bowen W, Tully D, Boness D, Bulheier B, and Marshall G. 2002. Prey-dependent foraging tactics and prey profitability in a marine mammal. Marine Ecology Progress Series 244:235-245. http://www.jstor.org/stable/24866378

Cadena EA, and Parham JF. 2015. Oldest known marine turtle? A new protostegid from the Lower Cretaceous of Colombia. PaleoBios 32:1-42. https://escholarship.org/uc/item/147611bv

Carr A, and Ogren LH. 1959. The ecology and migrations of sea turtles. 3. Dermochelys in Costa Rica. American Museum Novitates:1-29.

Christianen MJ, Herman PM, Bouma TJ, Lamers LP, van Katwijk MM, van der Heide T, Mumby PJ, Silliman BR, Engelhard SL, and van de Kerk M. 2014. Habitat collapse due to overgrazing threatens turtle conservation in marine protected areas. Proc R Soc London B: Biol Sci 281:20132890. 10.1098/rspb.2013.2890

Davenport J, and Clough W. 1985. The use of limbscales of "pseudoclaws" in food handling by young loggerhead turtles. Copeia 1985:786-788. 10.2307/1444774

Davenport J, Munks SA, and Oxford PJ. 1984. A comparison of the swimming of marine and freshwater turtles. Proceedings of the Royal Society of London Series B Biological Sciences 220:447-475. $10.1098 / \mathrm{rspb} .1984 .0013$

Deméré TA, McGowen MR, Berta A, and Gatesy J. 2008. Morphological and molecular evidence for a stepwise evolutionary transition from teeth to baleen in mysticete whales. Systematic Biology 57:15-37. https://doi.org/10.1080/10635150701884632

Domenici P, Batty RS, Simila T, and Ogam E. 2000. Killer whales (Orcinus orca) feeding on schooling herring (Clupea harengus) using underwater tail-slaps: kinematic analyses of field observations. Journal of Experimental Biology 203:283-294.

Fish FE. 2004. Structure and mechanics of nonpiscine control surfaces. IEEE Journal of Oceanic Engineering 29:605-621. 10.1109/JOE.2004.833213

Fish FE. 2016. Secondary Evolution of Aquatic Propulsion in Higher Vertebrates: Validation and Prospect. Integrative and Comparative Biology 56:1285-1297. https://doi.org/10.1093/icb/icw123

Fujii JA, Ralls K, and Tinker MT. 2014. Ecological drivers of variation in tool-use frequency across sea otter populations. Behavioral Ecology 26:519-526.

Gonzalez AF, and Lopez A. 2000. 'Kerplunking': Surface fluke-splashes during shallow-water bottom foraging by bottlenose dolphins. Marine Mammal Science 16:646-653. 10.1111/j.17487692.2000.tb00959.x

Gould SJ, and Vrba ES. 1982. Exaptation — a missing term in the science of form. Paleobiology 8:4-15. https://doi.org/10.1017/S0094837300004310

Hedges SB, Dudley J, and Kumar S. 2006. TimeTree: a public knowledge-base of divergence times among organisms. Bioinformatics 22:2971-2972. 10.1093/bioinformatics/bt1505

Hocking DP, Ladds MA, Slip DJ, Fitzgerald EMG, and Evans AR. 2017a. Chew, shake, and tear: Prey processing in Australian sea lions (Neophoca cinerea). Marine Mammal Science 33:541-557. $10.1111 / \mathrm{mms} .12384$

Hocking DP, Marx FG, Park T, Fitzgerald EMG, and Evans AR. 2017b. A behavioural framework for the evolution of feeding in predatory aquatic mammals. Proceedings of the Royal Society B:

Biological Sciences 284. 10.1098/rspb.2016.2750 
253

254

255

256

257

258

259

260

261

262

263

264

265

266

267

268

269

270

271

272

273

274

275

276

277

278

279

280

281

282

283

284

285

286

287

288

289

290

291

292

293

294

295

296

297

298

299

300

301

302

Houghton JDR, Woolmer A, and Hays GC. 2000. Sea turtle diving and foraging behaviour around the Greek Island of Kefalonia. Journal of the Marine Biological Association of the United Kingdom 80:761-762. undefined

Iwaniuk AN, and Whishaw IQ. 2000. On the origin of skilled forelimb movements. Trends in Neurosciences 23:372-376. https://doi.org/10.1016/S0166-2236(00)01618-0

Joyce WG, and Gauthier JA. 2004. Palaeoecology of Triassic stem turtles sheds new light on turtle origins. Proceedings of the Royal Society of London Series B: Biological Sciences 271:1-5. $10.1098 / \mathrm{rspb} .2003 .2523$

Kastelein RA, and Mosterd P. 1989. The excavation technique for molluscs of Pacific Walruses (Odobenus rosmarus divergens) under controlled conditions. Aquatic Mammals 15.

Kelley NP, and Motani R. 2015. Trophic convergence drives morphological convergence in marine tetrapods. Biology Letters 11:20140709. 10.1098/rsbl.2014.0709

Kelley NP, and Pyenson ND. 2015. Evolutionary innovation and ecology in marine tetrapods from the Triassic to the Anthropocene. Science 348. 10.1126/science.aaa3716

Kousha K, Thelwall M, and Abdoli M. 2012. The role of online videos in research communication: A content analysis of YouTube videos cited in academic publications. Journal of the American Society for Information Science and Technology 63:1710-1727. 10.1002/asi.22717

Limpus CJ, Couper P, and Read M. 1994. The loggerhead turtle, Caretta caretta, in Queensland: population structure in a warm temperature feeding area. Memoirs of the Queensland Museum 37:195.

Lloyd EA, and Gould SJ. 2017. Exaptation Revisited: Changes Imposed by Evolutionary Psychologists and Behavioral Biologists. Biological Theory 12:50-65. 10.1007/s13752-016-0258-y

Lutz PL, Musick JA, and Wyneken J. 2002. The biology of sea turtles. New York: CRC press.

Marshall CD, Maeda H, Iwata M, Furuta M, Asano S, Rosas F, and Reep RL. 2003. Orofacial morphology and feeding behaviour of the dugong, Amazonian, West African and Antillean manatees (Mammalia: Sirenia): functional morphology of the muscular-vibrissal complex. Journal of Zoology 259:245-260. 10.1017/S0952836902003205

Miller W, Schuster SC, Welch AJ, Ratan A, Bedoya-Reina OC, Zhao F, Kim HL, Burhans RC, Drautz DI, Wittekindt NE, Tomsho LP, Ibarra-Laclette E, Herrera-Estrella L, Peacock E, Farley S, Sage GK, Rode K, Obbard M, Montiel R, Bachmann L, Ingólfsson Ó, Aars J, Mailund T, Wiig Ø, Talbot SL, and Lindqvist C. 2012. Polar and brown bear genomes reveal ancient admixture and demographic footprints of past climate change. Proc Nat Acad Sci USA 109:E2382-E2390. 10.1073/pnas. 1210506109

Moreno AF, Escalona VHC, Rguez-Baron JM, Ruiz MG, and Hart CE. 2016. Functional morphology in marine turtle skulls. In: Rquez-Baron JM, Lara-Uc M, and Rodriguez RR, eds. Advances in research techniques for the study of sea turtles. New York: Nova Publishers, 1-26.

Motani R, Chen X-h, Jiang D-y, Cheng L, Tintori A, and Rieppel O. 2015. Lunge feeding in early marine reptiles and fast evolution of marine tetrapod feeding guilds. Scientific Reports 5. $10.1038 /$ srep08900

Patel SH, Dodge KL, Haas HL, and Smolowitz RJ. 2016. Videography Reveals In-Water Behavior of Loggerhead Turtles (Caretta caretta) at a Foraging Ground. Frontiers in Marine Science 3. 10.3389/fmars.2016.00254

Preen AR. 1996. Infaunal Mining: A Novel Foraging Method of Loggerhead Turtles. Journal of Herpetology 30:94-96. 10.2307/1564718

Schofield G, Katselidis KA, Dimopoulos P, Pantis JD, and Hays G, C. 2006. Behaviour analysis of the loggerhead sea turtle Caretta caretta from direct in-water observation. Endangered Species Research 2:71-79.

Seminoff JA, Jones TT, and Marshall GJ. 2006. Underwater behaviour of green turtles monitored with video-time-depth recorders: what's missing from dive profiles? Marine Ecology Progress Series 322:269-280. 
303 304 305 306

Taylor MA. 1987. How tetrapods feed in water: a functional analysis by paradigm. Zoological Journal of the Linnean Society 91:171-195.

Tinbergen N. 1962. Foot-paddling in gulls. British Birds 55:117-120.

Van Houtan KS, Andrews AH, Jones TT, Murakawa SKK, and Hagemann ME. 2016. Time in tortoiseshell: a bomb radiocarbon-validated chronology in sea turtle scutes. Proceedings of the Royal Society B: Biological Sciences 283. 10.1098/rspb.2015.2220

Van Houtan KS, Halley JM, and Marks W. 2015. Terrestrial basking sea turtles are responding to spatiotemporal sea surface temperature patterns. Biology Letters 11. 10.1098/rsbl.2014.0744

van Neer A, Jensen LF, and Siebert U. 2015. Grey seal (Halichoerus grypus) predation on harbour seals (Phoca vitulina) on the island of Helgoland, Germany. Journal of Sea Research 97:1-4. https://doi.org/10.1016/j.seares.2014.11.006

Weinrich MT, Schilling MR, and Belt CR. 1992. Evidence for acquisition of a novel feeding behaviour: lobtail feeding in humpback whales, Megaptera novaeangliae. Animal Behaviour 44:1059-1072. https://doi.org/10.1016/S0003-3472(05)80318-5 


\section{Table $\mathbf{1}$ (on next page)}

Functional definitions of observed types of limb use by feeding marine tetrapods.

${ }^{{ }^{T}}$ Feeding behaviors fell in one of three categories of feeding stages: capture, processing, and transport based on Hocking et al. (2017b). 
1

\begin{tabular}{|c|c|c|}
\hline BEHAVIOR & $\begin{array}{l}\text { FEEDING } \\
\text { STAGE }^{\mp}\end{array}$ & DEFINITION \\
\hline Digging & Capture & $\begin{array}{l}\text { Using one or both flippers or paws to remove benthic sediment in order to } \\
\text { access benthic food. }\end{array}$ \\
\hline Striking & Capture & Using one or both flippers, or tail, to forcibly hit prey, usually to stun. \\
\hline Tossing & Capture & Using flipper or tail to project prey into the air, usually used to stun prey. \\
\hline Kerplunking & Capture & $\begin{array}{l}\text { Slapping water surface with tail to cause a startle response in prey to aid in } \\
\text { capture. }\end{array}$ \\
\hline Leveraging & Processing & $\begin{array}{l}\text { Placing one or both flippers against benthic substrate to create tension while } \\
\text { pulling food from substrate with mouth. }\end{array}$ \\
\hline Swiping & Processing & $\begin{array}{l}\text { Moving one flipper against food to create tension while tearing food into } \\
\text { smaller pieces with mouth. }\end{array}$ \\
\hline Holding & Processing & $\begin{array}{l}\text { Using both flippers to keep food in place, either by squeezing flippers or } \\
\text { gripping with claws while pulling food apart with mouth. }\end{array}$ \\
\hline Pounding & Processing & $\begin{array}{l}\text { Using both flippers or paws to hold food while rapidly hitting against another } \\
\text { object. }\end{array}$ \\
\hline Corralling & Transport & $\begin{array}{l}\text { Using one or both flippers to guide loose food in a directed manner toward } \\
\text { mouth. }\end{array}$ \\
\hline Lobtailing & Transport & $\begin{array}{l}\text { Slapping water surface with tail during bubble-net feeding to corral prey } \\
\text { together. }\end{array}$ \\
\hline
\end{tabular}




\section{Figure 1}

Limb use in marine turtle foraging

(A) A hawksbill sea turtle holding a lobe coral (Porites lobata) to eat the black-brown protein sponge (Chondrosia chucalla) clinging to its surface in Kahekili, Maui USA, taken March 2010.

(B) A green turtle holding a mosaic jellyfish (Thysanostoma thysanura) in the water column near the ocean surface in the Similan Islands, Thailand, taken June 2017 (@ Rich

Carey/Shutterstock.com). (C) A hawksbill sea turtle leveraging against the reef substrate to pry away a magnificent sea anemone (Heteractis magnifica). This was a frame grab from a video in Cook's Bay, Moorea, French Polynesia from June 2013. (D) A green turtle leveraging against the reef substrate to pry away bites of red macroalgae (Amansia glomerata) in Kahekili, Maui, taken October 2016. (E) A loggerhead sea turtle swiping the shell of an Atlantic deep-sea scallop (Placopecten magellanicus) while it consumes the edible tissue. This is a frame grab from a video in the mid-Atlantic Bight USA taken on July 2009 and available courtesy of the Coonamessett Farm Foundation (Patel et al. 2016). (F) A green turtle swiping the stinging jellyfish (Cyanea barkeri) in the water column at Hook Island, Queensland, Australia, taken June 2017. Image credits by the authors, save $(B) \odot$ Rich Carey/Shutterstock.com and $(E)$ Coonamessett Farm Foundation. 

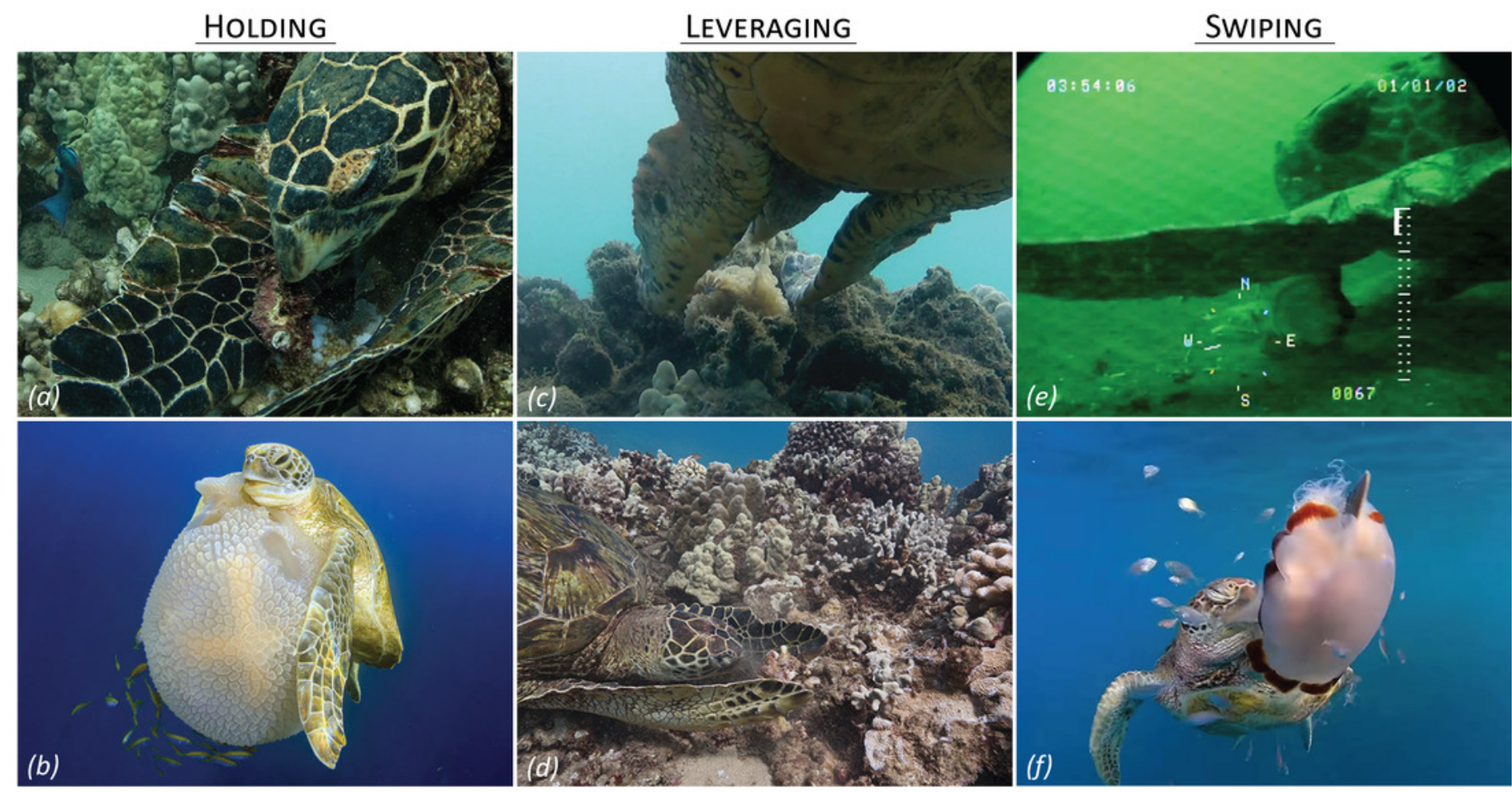
Figure 2 (on next page)

Evolutionary links between marine tetrapods known to use limbs while feeding and the diversity of body plans and types of limb use

Silhouettes show a representative body plan for each family. Specific feeding behaviors are listed for each family. 


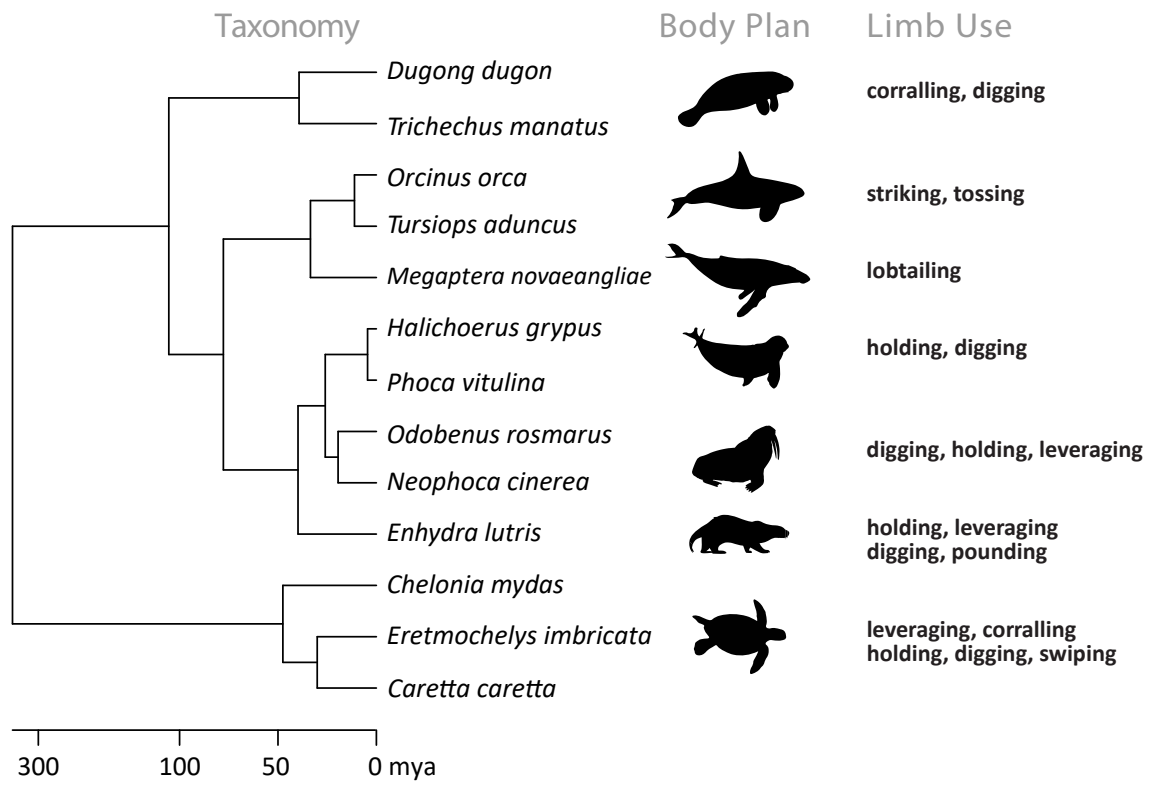

